\title{
Effect of an Organic Trace Mineral Premix on the Semen Quality, Testicular Morphology and Gene Expression Related to Testosterone Synthesis of Male Broiler Breeders
}

\section{-Author(s)}

Shan T' and Dai P'
Zhu Pll
Chen L' $^{\prime}$
Wu W"I
Li Y'
Li C'

College of Animal Science and Technology, Nanjing Agricultural University, Nanjing 210095, China

" Jiangsu Lihua Animal Husbandry Stock Co., LTD, Changzhou 213168, China

Shan T and Dai P contributed equally to this work

\section{Mail Address}

Corresponding author e-mail address Chunmei Li

College of Animal Science \& Technology Nanjing Agricultural University

No. 1 Weigang, Nanjing, Jiangsu, PR.China 210095

Tel: $\quad+86-25-84395971$

Email: chunmeili@njau.edu.cn

\section{Keywords}

Organic trace minerals; San Huang roosters; semen; testes.

\section{ABSTRACT}

In order to investigate the effect of organic trace minerals premix (OTM) on the reproductive performance of breeder roosters, a total of 240 San Huang roosters ( 23 weeks of age) were randomly divided into two treatments with six replicates of 20 roosters each. The first group $(n=120)$ was fed a basal diet containing an inorganic trace minerals premix (ITM) and the other group $(n=120)$ was fed the basal diet in which ITM was replaced by OTM. The experiment period was 22 weeks. Semen from one randomly-selected rooster per replicate was collected two weeks after the beginning of the experiment and other 10 times every two weeks. Another rooster per replicate was randomly selected at 30, 35, and 45 weeks of age, and sacrificed. Results showed that OTM did not affect relative organ weights. There was a significant increase in semen parameters in OTM group $(p<0.05)$, such as semen volume, semen density, and semen motility from 31 to 35 weeks. OTMfed roosters presented higher serum testosterone levels at 45 weeks of age, as well as higher testicular mRNA expression of the genes 3-beta dehydrogenase 2 (HSD3B2) and cytochrome P450 17A1 (CYP17A1) in the OTM-fed group at 45 weeks of age compared with those fed ITM $(p<0.05)$. Considering the results of the present study, it was concluded that feeding organic instead of inorganic trace minerals to male broilers breeders improves semen quality, which may be attributed to their better testicular development and higher expression of enzymes related to testosterone synthesis.

\section{INTRODUCTION}

Trace minerals are daily required for poultry growth and production, and are important intermediates in physiological and biochemical processes (Leeson et al., 2005). Three main types of trace mineral supplements are added to animal feeds: inorganic metal elements, such as ferrous (Fe) sulfate, zinc (Zn) oxide, and cupric chloride; primary simple organic compounds, like Fe citric acid and Zn gluconate; and organic trace minerals (OTM), such as copper glycine (Cu), iron glycine, and Zn methionine, among others (Saeid et al., 2013).

Organic trace minerals are chelates, formed by ionic bond or covalent bonds between the ligand (amino acids, small peptides, proteins, organic acids, and polysaccharide derivatives) and the metallic element. Organic trace minerals present better rate of absorption and utilization, good chemical stability, higher biological potency, and delay the antagonism among different minerals (Spears, 1996) compared with inorganic and simple organic trace minerals.

Lipid peroxidation is lethal to the sperm cells. The antioxidant glutathione peroxidase (GSH-Px), containing selenium (Se) in its activity center, which can improve GSH-Px catalytic activity directly, plays a crucial role in protecting sperm from oxidative damage (Mohammad 
Effect of an Organic Trace Mineral Premix on the Semen Quality, Testicular Morphology and Gene Expression Related to Testosterone Synthesis of Male Broiler Breeders
\& Moslemi, 2011). Selenium deficiency may slow down the development of the testis and epididymis, decreasing sperm density in semen, and increasing the production of abnormal sperm cells (Ahsan et al., 2014; Graupner et al., 2015).

Zinc is closely related with the antibacterial property of the seminal fluid. In addition, Zn plays a role in the stabilization of the sperm membrane, preventing its degradation (Taniguchi et al., 2007). The early development of the prostate requires high $\mathrm{Zn}$ levels, and its deficiency delays the development of secondary sexual characteristics, and reduces testosterone serum levels (Xu et al., 2015; Kothari \& Chaudhari, 2016).

Copper is required to maintain the stability of the luteotropic hormone ( $\mathrm{LH})$ and the follicle-stimulating hormone (FSH) in the serum. In addition, it enhances prostate capacity to secrete testosterone by improving the binding capacity of prostaglandin E2 (PGE2) to its receptor in the prostate (Rajeswari \& Swaminathan 2014; Wang et al., 2014). PEG2 can regulate the synthesis of LH through copper, increasing LH serum levels, thereby inducing testosterone secretion to promote the differentiation and maturation of sperm cells (Sakumoto et al., 2014).

High concentration of manganese $(\mathrm{Mn})$ chloride in diet can affect the development of testes, impairing spermatogenesis, interfering with sperm cell growth and development, and resulting in the production of abnormal sperm cells (Gu \& Hecht 1996). In addition, serum $\mathrm{Mn}$ excess induces significant changes in testes histology and physiology, and cause seminiferous tubule degeneration (Gabrielsen \& Tanrikut, 2016; McGough \& Jardine, 2017).

Most previous studies evaluated the effects of single inorganic element on the male reproductive system, and there is limited research on the effects of the dietary addition of OTM on the reproductive performance of male broiler breeders.

In the present study, rooster of the San Huang Chinese chicken breed were fed with $\mathrm{Zn}, \mathrm{Mn}, \mathrm{Cu}$, and Fe chelated with glycine, and Se yeast to determine their effect on semen quality, tissue accumulation, testicular morphology, serum testosterone level, and the gene expression of testosterone synthesis-related enzymes.

\section{MATERIALS AND METHODS}

\section{Birds, diets and experimental design}

The experiments were carried out on a farm belonging to Jiangsu Lihua Animal Husbandry Stock
Co, Ltd., Jiangsu, China. The San Huang roosters were housed in a commercial broiler breeder farm, and fed according to the Chicken Feed Regulations of Lihua. Roosters were used to semen collection every two days.

Birds were housed in individual cages and maintained under uniform management conditions (15 h light/day, $20-30{ }^{\circ} \mathrm{C}$ ). Water was provided ad libitum. The following feed allowances were supplied, according to age: $129 \mathrm{~g}$ per bird from 23 to 26 weeks, $121 \mathrm{~g}$ per bird from 27 to 34 weeks, and $131 \mathrm{~g}$ per bird from 35 to 45 weeks of age.

Two hundred and forty San Huang roosters with 23 weeks of age were randomly divided into two treatments, with six replicates of 20 birds each. In the control treatment, the basal diet (Table 1) was supplemented with $100 \%$ inorganic trace minerals (ITM) at levels of 55, 60, 5.5, 70, and $0.15 \mathrm{mg}$ of $\mathrm{Zn}$, $\mathrm{Mn}, \mathrm{Cu}, \mathrm{Fe}$, and Se per $\mathrm{kg}$ of diet, respectively, in the form of sulfate, except for Se, which was added as sodium selenite. The inorganic compounds contained $34.5 \% \mathrm{Zn}, 31.8 \% \mathrm{Mn}, 25 \% \mathrm{Cu}, 30 \% \mathrm{Fe}$, and $0.45 \%$ $\mathrm{Se}$, according to the products' specifications. In the second treatment, the basal diet did not contain ITM and was supplemented with $100 \%$ OTM, at the levels of $45,49,4.5,58$, and $0.13 \mathrm{mg}$ of $\mathrm{Zn}, \mathrm{Mn}, \mathrm{Cu}, \mathrm{Fe}$, and Se per $\mathrm{kg}$ of diet, respectively, as methionine chelates,

Table 1 - Composition of the basal diet.

\begin{tabular}{|c|c|}
\hline Item & Composition, \% \\
\hline \multicolumn{2}{|l|}{ Ingredients } \\
\hline Corn & 63.91 \\
\hline Soybean meal & 9.60 \\
\hline Rice bran & 23.57 \\
\hline Limestone & 1.62 \\
\hline Liquid methionine & 0.04 \\
\hline Choline chloride & 0.13 \\
\hline Sodium chloride & 0.30 \\
\hline Dicalcium phosphate & 0.66 \\
\hline Vitamin premix ${ }^{1}$ & 0.05 \\
\hline Minerals premix² & 0.12 \\
\hline \multicolumn{2}{|l|}{ Calculated composition } \\
\hline Metabolizable energy, kcal/kg & 2,76 \\
\hline Crude protein & 12.98 \\
\hline Methionine & 0.28 \\
\hline Lysine & 0.58 \\
\hline Calcium & 0.81 \\
\hline Total phosphorus & 0.80 \\
\hline \multicolumn{2}{|c|}{$\begin{array}{l}\text { 'Provided per kilogram of diet: vitamin A, } 6,000 \mathrm{IU} \text {; cholecalciferol, 2,500 IU; vitamin } \\
\mathrm{E}, 40 \mathrm{mg} \text {; menadione, } 1.5 \mathrm{mg} \text {; thiamine, } 3 \mathrm{mg} \text {; riboflavin, } 12 \mathrm{mg} \text {; pyridoxine, } 6 \mathrm{mg} \text {; } \\
\text { vitamin } \mathrm{B}_{12}, 35 \mathrm{\mu g} \text {; pantothenic acid, } 10 \mathrm{mg} \text {; niacin, } 60 \mathrm{mg} \text {; folic acid, } 0.8 \mathrm{mg} \text {; biotin, } \\
0.225 \mathrm{mg} \text {. }\end{array}$} \\
\hline \multicolumn{2}{|c|}{$\begin{array}{l}{ }^{2} \text { Provided per kilogram of diet: copper, } 5.5 \text { mg; iron, } 70 \text { mg; zinc, } 55 \text { mg; manganese, } \\
60 \text { mg; iodine, } 0.4 \text { mg; selenium, } 0.15 \mathrm{mg} \text {. }\end{array}$} \\
\hline
\end{tabular}


Shan T, Dai P, Zhu P, Chen L Wu W, Li Y, Li C
Effect of an Organic Trace Mineral Premix on the Semen Quality, Testicular Morphology and Gene Expression Related to Testosterone Synthesis of Male Broiler Breeders except for glycine-Fe and Se-yeast. The organic trace mineral product specifications are 16\% Zn, 13\% $\mathrm{Mn}, 15 \% \mathrm{Cu}, 17 \% \mathrm{Fe}$, and $0.2 \% \mathrm{Se}$. The OTM were purchased from Novus International Trade Co, Ltd. (Shanghai, China).

The basal diet was based on corn and soybean meal basal and formulated to contain adequate levels of all nutrients, as recommended by the National Research Council (NRC, 1994). The experimental period was 22 weeks. One rooster was randomly selected per replicate for semen collection. Semen was collected for the first time 2 weekss after the beginning of the treatments, and 10 times thereafter in 2-week intervals (at 27, 29, 31, 33, 35, 37, 39, 41, 43, and 45 weeks of age). One rooster per replicate was randomly selected at three time points $(30,35$, and 45 weeks of age) and sacrificed for blood and organ collection.

\section{Sample collection}

Blood samples were collected in plastic tubes and centrifuged at $1369.6(\times \mathrm{g})$ for $15 \mathrm{~min}$ at $4{ }^{\circ} \mathrm{C}$. The serum was separated and stored at $-20^{\circ} \mathrm{C}$ until assayed for testosterone levels. Internal organs (heart, liver and spleen) and reproductive organs (testis and epididymis) were excised and immediately weighed. A subsample from each testis sample was fixed in $4 \%$ paraformaldehyde and processed for histological examination; the remaining testes were stored in liquid nitrogen for RT-PCR.

\section{Determination of the five evaluated trace minerals concentrations in the feed, serum and testis}

Diet and testis samples $(0.5 \mathrm{~g})$, as well as blood samples $(0.5 \mathrm{~mL})$ were digested with nitric acid $(75 \%)$ and perchloric acid $(25 \%)$ overnight at $25^{\circ} \mathrm{C}$. After the solution became faint yellow, the samples were placed in a digestion System. After digestion, the solution was removed to $25-\mathrm{mL}$ volumetric flask, then levels of the five supplemented trace minerals $(\mathrm{Zn}, \mathrm{Mn}, \mathrm{Cu}, \mathrm{Fe}$, and Zn) were measured by inductively coupled plasma optical emission spectrometry (ICP-OES, Perkin Elmer Optima 2100 DV, USA). The results were determined against the standard curve of each element.

\section{Semen quality analysis}

The semen was collected by dorso-abdominal massage (Burrows \& Quinn, 1937). A semen sample was placed into a sterile stoppered graduated measuring glass, and its volume was immediately measured and recorded. After collection, the sample was incubated at $37^{\circ} \mathrm{C}$ until analysis. A $10-\mu \mathrm{L}$ sample was diluted $(1: 20)$ in hydrosaline solution ( $3 \%, \mathrm{wt} / \mathrm{vol} ; \mathrm{NaCl})$ to determine sperm concentration using hemocytometer. Sperm motility was visually assessed in at least 10 microscopic fields, and the percentage of moving sperm relative to non-motile cells was calculated. Sperm morphology was assessed in 300 sperm cells per air-dried sample.

\section{Testis histology}

The testis samples fixed in formaldehyde were dehydrated in graded ethanol series, cleared in xylene, and embedded in paraffin wax. Sections $(5-\mu \mathrm{m}$ thickness) were then cut and were with hematoxylin and eosin (HE). The stained sections were mounted on slides and examined under light microscopy $(400 \times)$.

\section{Radioimmunoassay}

The serum concentrations of testosterone were determined by the Nanjing General Hospital of the Nanjing Military Command using a 125 I-labeled radioligand double-antibody RIA kit. The commercial RIA kit was purchased from Beijing Beifang Institute of Biotechnology. The intra- and inter-assay coefficients of variation were less than $10 \%$ for testosterone.

\section{Reverse transcription-polymerase chain reaction}

Total RNA was extracted from the tissue using a RNeasy mini kit (Qiagen, China) according to the manufacturer's instructions. The concentration and purity of the isolated total RNA was determined spectrophotometrically at 260 and $280 \mathrm{~nm}$ with a Nanodrop 8000 (Thermo Fisher Scientific, Wilmington, USA). The total RNA (1 $\mu \mathrm{g})$ was reverse transcribed to cDNA with an Omniscript Reverse Transcription kit (Takara, Japan) with Oligo-dT primers (Takara, Japan) according to the manufacturer's instructions. The target fragments were quantified by real-time PCR using a QuantiTectTMSYBR Green PCR Kit (F Hoffmann-La Roche Ltd., Switzerland) with $100 \mathrm{ng}$ of the cDNA template. The gene expression data were normalized to $\beta$-actin expression. The specific primer sets, designed using Primer 5 Plus program, are described in Table 2. For the quantification of real-time PCR results, the threshold cycle Ct was determined for each reaction. $C t$ values for each gene of interest were normalized to the housekeeping gene; PCR amplification efficiencies were taken into account by amplifying various amounts of target cDNA for each reaction. Normalized values were used to calculate the degree of induction or inhibition expressed as a "fold difference" compared with normalized control values. 
Shan T, Dai P, Zhu P, Chen L Wu W, Li Y, Li C
Effect of an Organic Trace Mineral Premix on the Semen Quality, Testicular Morphology and Gene Expression Related to Testosterone Synthesis of Male Broiler Breeders

\section{Trace minerals concentrations in the diet, serum and testis}

The trace minerals levels were evaluated in the diet, and in the serum and testis of the birds fed OTM or ITM at 30, 35, and 45 weeks of age (Table 5).

The OTM diet presented lower Mn and $\mathrm{Zn}$ levels $(p<0.001)$ than the ITM diet, but the levels of the other evaluated trace minerals $(\mathrm{Cu}, \mathrm{Fe}, \mathrm{Se})$ were not different. Testicular Zn level at 45 weeks of age were higher $(p<0.05)$ in the OTM group compared with the ITM group. In 30-week-old birds, serum Fe level was lower in the OTM group compared with the ITM group $(p<0.01)$, but not at the other evaluated ages. Serum $\mathrm{Mn}$ levels in the OTM group were higher than in the ITM group at 45 weeks $(p<0.05)$.

\section{Testicular histology}

Figure 1 shows the testicular histology of roosters evaluated at 30, 35, and 45 weeks of age. As shown in Fig. 1, the testicular histology was not different

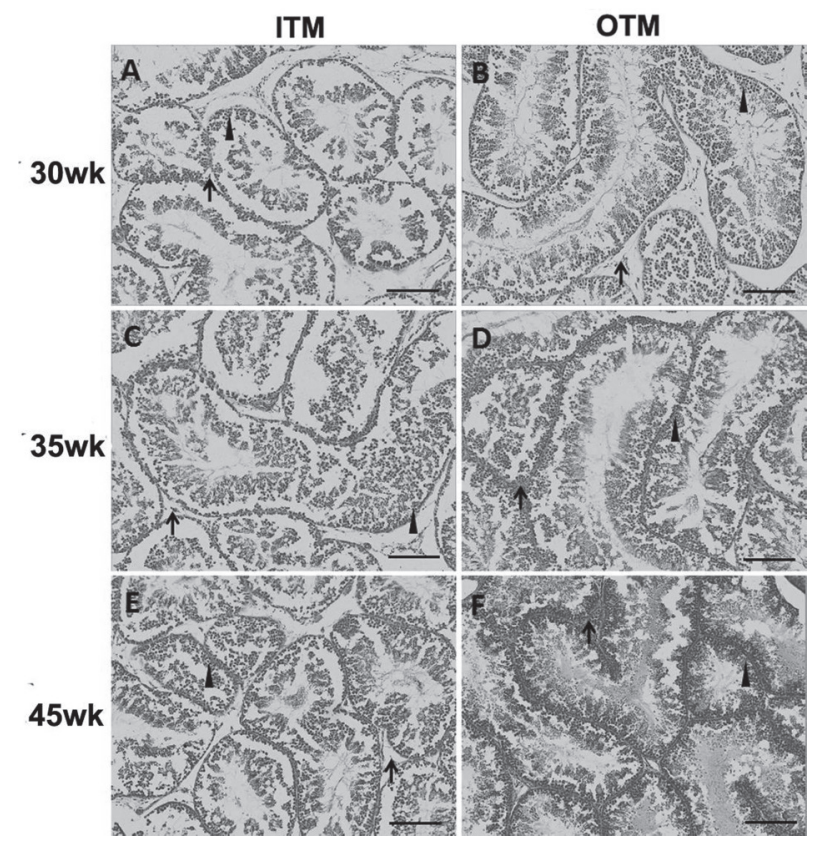

Figure 1 - Effects of dietary organic trace minerals premix (OTM) on spermatogonia and Leydig cells of the testes of male broiler breeders at 30 ( $A$ and B), 35 (C and D) and 45 (E and F) weeks of age. Sections were stained with hematoxylin and eosin (HE). Bar = $100 \mu \mathrm{m}$. Arrowhead shows spermatogonia and primary spermatocyte cells. Arrow shows Leydig cells $(400 \times)$.

Table 3 - Effect of dietary organic trace minerals premix on semen quality.

\begin{tabular}{lcccccc}
\hline \multirow{2}{*}{ Semen Parameters } & \multicolumn{2}{c}{$25-29$ weeks } & \multicolumn{2}{c}{$31-35$ weeks } & \multicolumn{2}{c}{$37-45$ weeks } \\
\cline { 2 - 6 } & ITM & OTM & ITM & OTM & ITM & OTM \\
\hline Volume, $\mathrm{mL}$ & $0.40 \pm 0.24$ & $0.47 \pm 0.18$ & $0.37 \pm 0.14$ & $0.52 \pm 0.12^{* *}$ & $0.34 \pm 0.08$ & $0.54 \pm 0.10^{* * *}$ \\
Density, $\times 10 \% \mathrm{~mL}$ & $3.90 \pm 0.65$ & $4.45 \pm 1.01$ & $3.74 \pm 0.66$ & $4.76 \pm 0.52^{* * *}$ & $3.84 \pm 0.45$ & $4.61 \pm 0.40$ \\
Motility, \% & $80.50 \pm 9.84$ & $85.42 \pm 3.96$ & $82.00 \pm 6.21$ & $87.50 \pm 3.53^{* *}$ & $84.33 \pm 4.57$ & $86.50 \pm 2.53$ \\
Abnormal morphology, \% & $8.05 \pm 0.75$ & $5.91 \pm 0.68^{*}$ & $9.73 \pm 0.85$ & $6.72 \pm 0.45^{* *}$ & $8.67 \pm 0.55$ & $6.62 \pm 0.35^{* *}$ \\
\hline
\end{tabular}

$\mathrm{ITM}=$ inorganic trace minerals premix; OTM $=$ organic trace minerals premix. The values shown are the mean \pm SEM of 6 animals per group. ${ }^{*} p<0.05,{ }^{*} p<0.01,{ }^{* *} p<0.001$. 
Table 4 - Effect of dietary organic trace minerals premix on body weight and the relative organ weight.

\begin{tabular}{lcccccc}
\hline & \multicolumn{2}{c}{30 weeks } & \multicolumn{2}{c}{35 weeks } & \multicolumn{2}{c}{45 weeks } \\
\cline { 2 - 6 } Item & ITM & OTM & ITM & OTM & ITM & OTM \\
\hline Body weight, $\mathrm{kg}$ & $4.41 \pm 0.07$ & $4.15 \pm 0.07$ & $4.56 \pm 0.12$ & $4.35 \pm 0.13$ & $4.44 \pm 0.11$ & $4.25 \pm 0.14$ \\
Heart, g & $22.49 \pm 0.56$ & $20.34 \pm 0.61$ & $23.61 \pm 0.64$ & $21.16 \pm 0.85$ & $21.13 \pm 0.71$ & $21.14 \pm 0.45$ \\
Relative Heart (\%) & $0.51 \pm 0.01$ & $0.49 \pm 0.01$ & $0.52 \pm 0.02$ & $0.49 \pm 0.03$ & $0.48 \pm 0.01$ & $0.49 \pm 0.09$ \\
Liver, g & $66.01 \pm 1.50$ & $58.39 \pm 3.30$ & $45.54 \pm 2.11$ & $47.26 \pm 2.98$ & $43.11 \pm 3.63$ & $47.53 \pm 3.90$ \\
Relative Liver (\%) & $1.46 \pm 0.05$ & $1.40 \pm 0.07$ & $1.00 \pm 0.05$ & $1.08 \pm 0.05$ & $0.96 \pm 0.05$ & $1.11 \pm 0.06$ \\
Spleen, g & $4.18 \pm 0.24$ & $3.89 \pm 0.15$ & $3.71 \pm 0.11$ & $4.06 \pm 0.21$ & $4.46 \pm 0.46$ & $4.43 \pm 0.29$ \\
Relative Spleen (\%) & $0.09 \pm 0.01$ & $0.09 \pm 0.01$ & $0.08 \pm 0.01$ & $0.09 \pm 0.01$ & $0.10 \pm 0.01$ & $0.11 \pm 0.01$ \\
Testis, g & $24.63 \pm 1.87$ & $24.29 \pm 1.72$ & $23.02 \pm 1.47$ & $21.02 \pm 2.56$ & $19.46 \pm 1.97$ & $20.73 \pm 2.45$ \\
Relative Testis (\%) & $0.55 \pm 0.05$ & $0.59 \pm 0.04$ & $0.51 \pm 0.04$ & $0.49 \pm 0.06$ & $0.44 \pm 0.04$ & $0.49 \pm 0.05$ \\
\hline
\end{tabular}

ITM = inorganic trace minerals premix; OTM = organic trace minerals premix. The values shown are the mean \pm SEM of 6 animals per group. The relative organ weights were calculated as the organ weights divided by BW (g/g BW).

between ITM- and OTM-fed roosters at 30 and 35 weeks of age. The seminiferous epithelium was tighter in the OTM group than in the ITM group at 45 weeks of age, and the number of spermatogonia, primary spermatocytes and Leydig cells were higher in the OTM group compared with the ITM group.

\section{Serum testosterone concentrations and mRNA expression levels of enzymes related to testosterone synthesis}

Figure 2 shows the serum testosterone levels of 30-, 35-, and 45-week-old roosters. Those fed OTM presented higher testosterone levels at $35(p<0.05)$ and $45(p<0.01)$ weeks of age than those fed ITM, but not at 30 weeks of age.

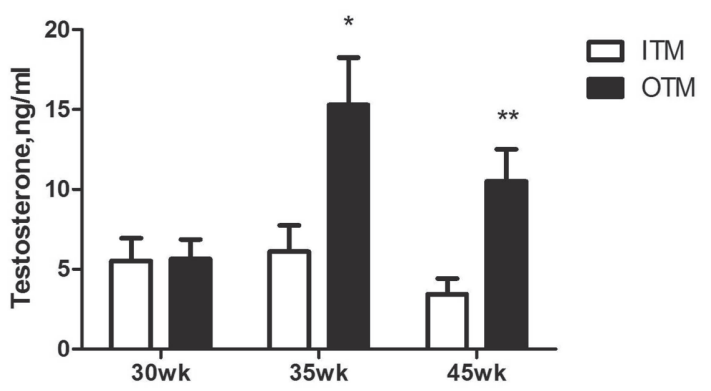

Figure 2 - Effect of dietary organic trace minerals premix (OTM) on serum testosterone levels of roosters at $30,35,45$ weeks of age. The values shown are the mean \pm SEM of 6 animals per treatment. ${ }^{*} p<0.05,{ }^{* *} p<0.01$. ITM $=$ inorganic trace minerals premix.

Figure 3 presents the mRNA expression levels of enzymes related to testosterone synthesis in the testes of 30-, 35-, and 45-week-old roosters. Higher mRNA

Table $\mathbf{5}$ - The concentrations of 5 trace minerals in fodder, serum and testis.

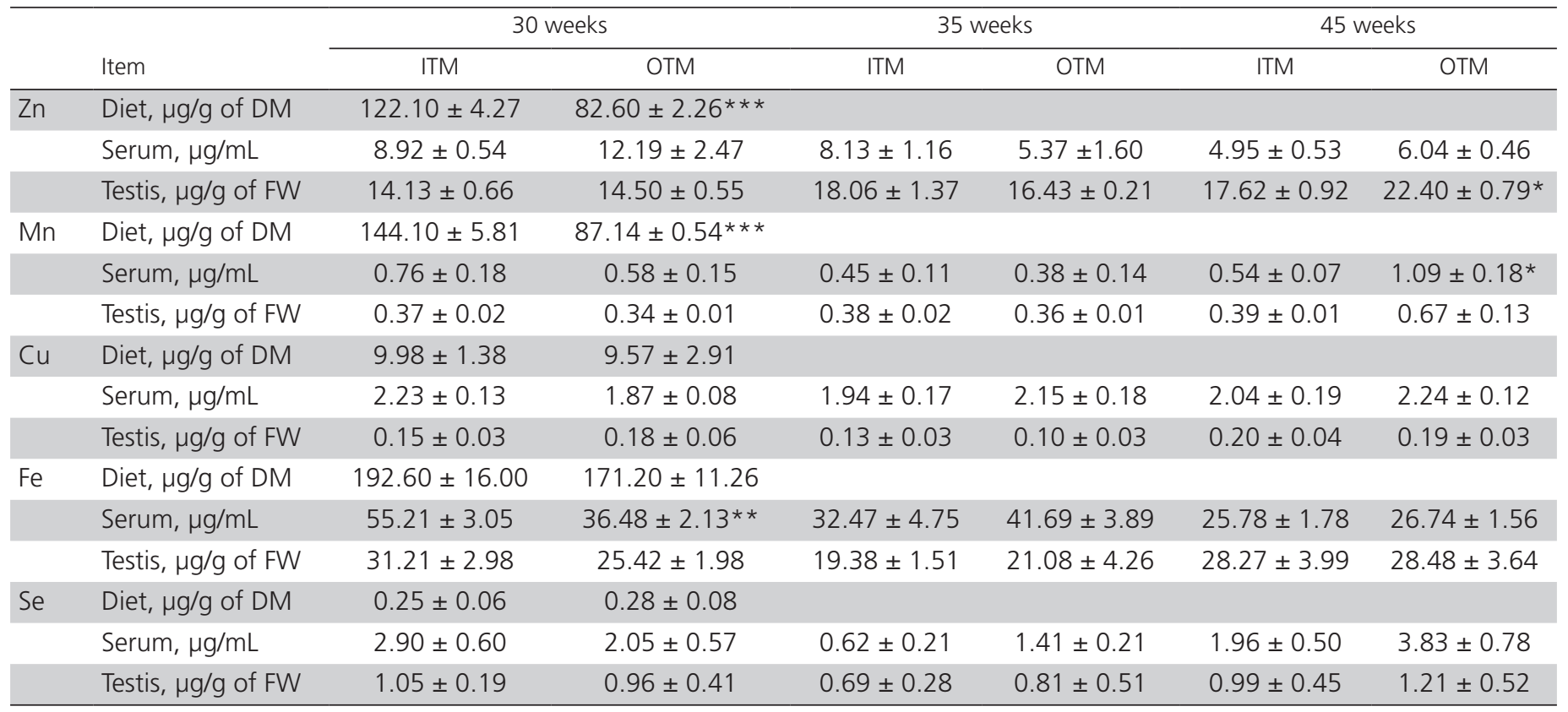

ITM = inorganic trace minerals premix; OTM = organic trace minerals premix; DM = dry matter; FW = fresh weight (the weight of tissue used for detection). The values shown are the mean \pm SEM of 6 animals per group. ${ }^{*} p<0.05,{ }^{* *} p<0.01,{ }^{* * *} p<0.001$. 
expression levels of the HSD3B2 and CYP17A1 genes were determined in the OTM-fed roosters compared with those fed ITM at 45 weeks of age $(p<0.05)$ (Fig. $3 \mathrm{~A}$ and $3 \mathrm{~B}$ ), but not at younger ages ( 30 and 35 weeks of age). In contrast with the ITM-fed birds, the mRNA expression level of the HSD17B4 gene in the OTMfed birds was higher at $30(p<0.01)$ and $35(p<0.05)$ weeks of age, but lower at $45(p<0.05)$ weeks of age (Fig. 3C). The mRNA expression of the CYP19A1 gene was lower in the OTM-fed birds at 30 weeks of age $(p<0.001)$, and higher at 35 and 45 weeks of age $(p<0.01)$ than in those fed ITM (Fig 3D).
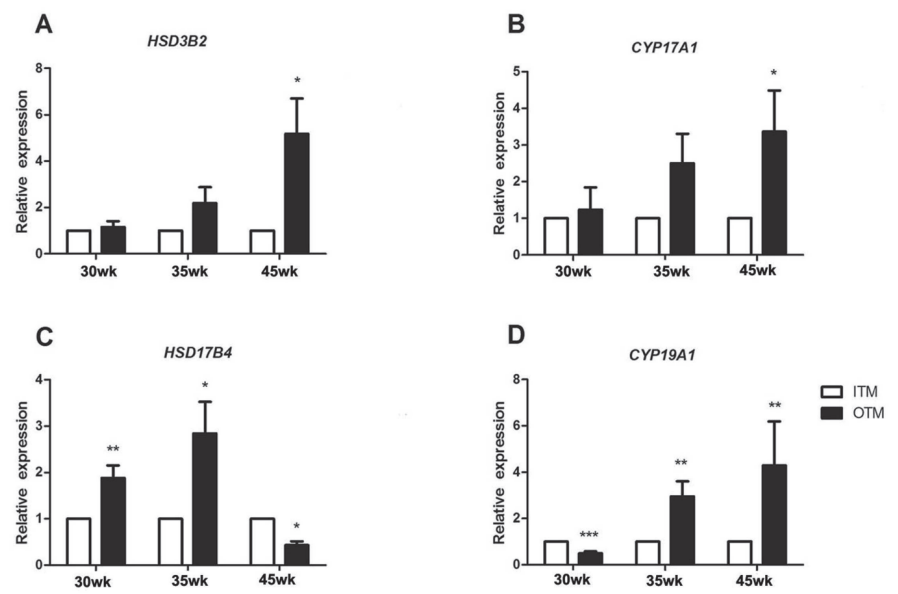

Figure 3 - Effect of dietary organic trace minerals premix (OTM) on the mRNA expression level of the genes hydroxysteroid 3-beta dehydrogenase 2 (HSD3B2), cytochrome P450 17A1 (CYP17A1), hydroxysteroid 17-beta dehydrogenase 4 (HSD17B4) and cytochrome P450 19A1 (CYP19A1) in the testes of roosters at 30, 35, 45 weeks of age. The values shown are mean \pm SEM of 6 animals per group. ${ }^{*} p<0.05,{ }^{* *} p<0.01$, $* * * p<0.001$

\section{DISCUSSION}

This is the first report that focuses on the effects of the OTM on semen quality and testosterone synthesis in San Huang breeder roosters. The present study demonstrated that OTM had a positive impact on the growth of closed-packed spermatogonia and Leydig cells, and improved the semen quality of roosters from 31 to 35 weeks of age. At 45 weeks of age, roosters fed OTM presented significantly higher serum testosterone levels, as well as higher mRNA expression levels of the HSD3B2 and CYP17A1 genes in the testes.

Several markers are used to evaluate semen quality, such as semen volume, sperm density, sperm motility, and abnormal morphology. In the mammalian studies, trace minerals have been shown to be essential for improving semen quality. There is a positive correlation between OTM and high semen quality in broilers (Abdallah et al., 2009; Atig et al., 2013). The absence of $\mathrm{Zn}$ or Mn may suppress enzyme systems required for sperm motility and sperm count in rats (Yamaguchi et al., 2009; Babaei \& Abshenas, 2013). The trace elements of $\mathrm{Zn}, \mathrm{Mn}$, and Se enhance spermatogenesis and improve semen quality in broiler breeders (Barber et al., 2005). It was reported that the supplementation of OTM, including $\mathrm{Zn}, \mathrm{Cu}, \mathrm{Co}$, and $\mathrm{Mn}$, improved the semen quality of bulls, even after freezing, compared with ITM (Rowe et al., 2013; Rowe et al., 2014). In the present study, the OTM-fed roosters presented better semen parameters, such as semen volume, density, motility, and number of normal sperm during the entire experimental period compared with those fed ITM, indicating that OTM improved semen quality.

Dietary organic mineral sources increase the intestinal absorption of trace elements as they do not form indigestible complexes with dietary antinutrient compounds (Świątkiewicz et al., 2014). Due to their high bioavailability, OTM supplementation of broiler diets is an efficient method to reduce trace mineral excretion in the environment (Bao et al., 2007). In the present study, the levels of the five trace minerals were higher in the ITM diet than in the OTM diet. However, both ITM- and OTM-fed roosters presented similar serum and testicular levels of these trace minerals, indicating that the organic forms had higher bioavailability and absorption rate than the inorganic forms.

A previous study reported that feeding high OTM levels increased pregnancy rate to artificial insemination of beef cows compared with ITM either at low or high levels (Stanton et al., 2000). Angus heifers fed OTM presented a higher number of fertilized oocytes than those fed ITM (Lamb et al., 2008). Feeding OTM benefitted sow reproductive performance compared with ITM (Peters \& Mahan, 2008). In present study, the seminiferous epithelium was tighter in the OTM-fed roosters, which is consistent with mentioned previous studies showing that feeding OTM may improve reproductive performance.

Testosterone plays a vital role in the development of the testis, epididymis, an prostate, and on semen quality (Murashima et al., 2015). In the present study, dietary OTM increased serum testosterone levels. In order to investigate the potential mechanisms underlying the OTM-induced testosterone increase, the mRNA expression of enzymes related to the testosterone biosynthesis were measured. The HSD3B2, CYP17A1, hydroxysteroid 17-beta dehydrogenase 4 (HSD17B4) genes are known to encode enzymes involved in biosynthesis of testosterone (Taniguchi et al., 2007; Pierce et al., 2010; Rabbani et al., 2012). Cytochrome P450 19A1 (CYP19A1) converts androstenedione 
Effect of an Organic Trace Mineral Premix on the Semen Quality, Testicular Morphology and Gene Expression Related to Testosterone Synthesis of Male Broiler Breeders

Graupner A, Instanes C, Andersen JM, Brandt-Kjelsen A, Dertinger SD, Salbu $B$, et al. Genotoxic effects of two-generational selenium deficiency in mouse somatic and testicular cells. Mutagenesis 2015;30(2):217-225.

Gu W, Hecht NB. Developmental expression of glutathione peroxidase, catalase, and manganese superoxide dismutase mRNAs during spermatogenesis in the mouse. Journal of Andrology 1996;17:256-62.

Hosono S, Matsuo K, Ito H, Watanabe M, Hirose K, Nakanishi T, et al. Interaction between CYP19A1 polymorphisms and body mass index in the risk of endometrial cancer in postmenopausal Japanese women. Asian Pacific Organization for Cancer Prevention 2011;12:2747-52.

Kothari RP, Chaudhari AR. Zinc levels in seminal fluid in infertile males and its relation with serum free testosterone. Journal of Clinical and Diagnostic Research 2016;10(5):CC05-CC10.

Lamb GC, Brown DR, Larson JE, Dahlen CR, DiLorenzo N, Arthington JD, et al. Effect of organic or inorganic trace mineral supplementation on follicular response, ovulation, and embryo production in superovulated Angus heifers. Animal Reproduction Science 2008;106:221-231.

Leeson S, Taylor-Pickard J, Tucker L. Trace mineral requirements of poultryvalidity of the NRC recommendations. In: Taylor-Pickard JA, Tucker L. Re-defining mineral nutrition. Nottingham: University Press; 2005. p.107-117.

McGough D, Jardine L. A two-generation inhalation reproductive toxicity study upon the exposure to manganese chloride. Neurotoxicology 2017;58:194-202

Mohammad K, Moslemi ST. Selenium-vitamin E supplementation in infertile men: effects on semen parameters and pregnancy rate. International Journal of General Medicine 2011:4:99-104.

Murashima A, Kishigami S, Thomson A, Yamada G. Androgens and mammalian male reproductive tract development. Biochimica et Biophysica Acta: Gene Regulatory Mechanisms 2015;1849:163-170.

Peters J, Mahan D. Effects of dietary organic and inorganic trace mineral levels on sow reproductive performances and daily mineral intakes over six parities. Journal of Animal Science 2008;86:2247-2260.

Pierce SB, Walsh T, Chisholm KM, Lee MK, Thornton AM, Fiumara A, et al. Mutations in the DBP-deficiency protein HSD17B4 cause ovarian dysgenesis, hearing loss, and ataxia of Perrault Syndrome. The American Journal of Human Genetics 2010;87:282-288.

Rabbani B, Mahdieh N, Ashtiani MTH, Setoodeh A, Rabbani A. In silico structural, functional and pathogenicity evaluation of a novel mutation: an overview of HSD3B2 gene mutations. Gene 2012;503:215-221.

Rajeswari S, Swaminathan S. Role of copper in health and diseases. International Journal of Biological Sciences 2014;10:94-107.

Rowe M, Powell J, Kegley E, Lester T, Rorie R. Effect of supplemental tracemineral source on bull semen quality. The Professional Animal Scientist 2014;30:68-73.

Rowe M, Powell J, Kegley E, Lester T, Williams C, Page R, et al. Influence of organic versus inorganic trace mineral supplementation on bull semen quality. AAES Research Series 2013;597:11-13.

Saeid A, Chojnacka K, Korczyński M, Korniewicz D, Dobrzański Z. Biomass of Spirulina maxima enriched by biosorption process as a new feed supplement for swine. Journal of Applied Phycology 2013;25:667-75.

Sakumoto R, Hayashi K, Takahashi T. Different expression of PGE synthase, PGF receptor, TNF, Fas and oxytocin in the bovine corpus luteum of the estrous cycle and pregnancy. Reproductive Biology 2014;14:115-121.

Spears JW. Organic trace minerals in ruminant nutrition. Animal Feed Science and Technology 1996;58:151-163. 
Shan T, Dai P, Zhu P, Chen L Wu W, Li Y, Li C
Stanton T, Whittier J, Geary T, Kimberling C, Johnson A. Effects of trace mineral supplementation on cow-calf performance, reproduction, and immune function. The Professional Animal Scientist 2000;16:121-127.

Świątkiewicz S, Arczewska-Włosek A, Jozefiak D. The efficacy of organic minerals in poultry nutrition: review and implications of recent studies. World's Poultry Science Journal 2014;70:475-486.

Taniguchi F, Couse JF, Rodriguez KF, Emmen JM, Poirier D, Korach KS. Estrogen receptor- $\alpha$ mediates an intraovarian negative feedback loop on thecal cell steroidogenesis via modulation of Cyp17a1 (cytochrome P450, steroid $17 \alpha$-hydroxylase/17, 20 lyase) expression. The FASEB Journal 2007;21:586-595.
Effect of an Organic Trace Mineral Premix on the Semen Quality, Testicular Morphology and Gene Expression Related to Testosterone Synthesis of Male Broiler Breeders

Wang $F$, Liu $S$, Sun $Q$, Zhang $L$, Song $Y$, Sheng $W$, et al. Urinary VEGF and PGE2 levels and the association with arsenical metabolites in copper-smelting workers. Occupational and Environmental Medicine 2014;71(10):675-680

Xu X, Chen X, Hu H, Dailey AB, Taylor BD. Current opinion on the role of testosterone in the development of prostate cancer: a dynamic model. BMC cancer 2015;15:806.

Yamaguchi S, Miura C, Kikuchi K, Celino FT, Agusa T, Tanabe S, et al. Zinc is an essential trace element for spermatogenesis. Proceedings of the National Academy of Sciences 2009;106:10859-10864. 